\title{
Coupling plowing of cartilage explants with gene expression in models for synovial joints
}

\author{
Correro-Shahgaldian, M R ; Colombo, V ; Spencer, N D ; Weber, Franz E ; Imfeld, T ; Gallo, L M
}

\begin{abstract}
Articular cartilage undergoes complex loading modalities generally including sliding, rolling and plowing (i.e. the compression by a condyle normally to the tissue surface under simultaneously tangential displacement, thus generating a tractional force due to tissue deformation). Although in in vivo studies it was shown that excessive plowing can lead to osteoarthritis, little quantitative experimental work on this loading modality and its mechanobiological effects is available in the literature. Therefore, a rolling/plowing explant test system has been developed to study the effect on pristine cartilage of plowing at different perpendicular forces. Cartilage strips harvested from bovine nasal septa of 12-months-old calves were subjected for $2 \mathrm{~h}$ to a plowing-regime with indenter normal force of 50 or $100 \mathrm{~N}$ and a sliding speed of $10 \mathrm{~mm} \mathrm{~s}(-1) .50 \mathrm{~N}$ produced a tractional force of $1.2 \pm 0.3 \mathrm{~N}$, whereas $100 \mathrm{~N}$ generated a tractional force of $8.0 \pm 1.4 \mathrm{~N}$. Furthermore, quantitative-real-time polymerase chain reaction experiments showed that TIMP-1 was 2.5x up-regulated after $50 \mathrm{~N}$ plowing and $2 \mathrm{x}$ after $100 \mathrm{~N}$ plowing, indicating an ongoing remodeling process. The expression of collagen type-I was not affected after $50 \mathrm{~N}$ plowing but it was up-regulated (6.6x) after $100 \mathrm{~N}$ plowing, suggesting a possible progression to an injury stage of the cartilage, as previously reported in cartilage of osteoarthritic patients. We conclude that plowing as performed by our mimetic system at the chosen experimental parameters induces changes in gene expression depending on the tractional force, which, in turn, relates to the applied normal force.
\end{abstract}

DOI: https://doi.org/10.1016/j.jbiomech.2011.06.021

Posted at the Zurich Open Repository and Archive, University of Zurich

ZORA URL: https://doi.org/10.5167/uzh-54972

Journal Article

Accepted Version

Originally published at:

Correro-Shahgaldian, M R; Colombo, V; Spencer, N D; Weber, Franz E; Imfeld, T; Gallo, L M (2011). Coupling plowing of cartilage explants with gene expression in models for synovial joints. Journal of Biomechanics, 44(13):2472-2476.

DOI: https://doi.org/10.1016/j.jbiomech.2011.06.021 


\section{Coupling plowing of cartilage explants with gene expression in models for synovial joints}

Maria Rita Correro-Shahgaldian ${ }^{1,2,3}$, Vera Colombo ${ }^{1}$, Nicholas D. Spencer $^{3}$, Franz E. Weber ${ }^{2}$, Thomas Imfeld ${ }^{4}$ and Luigi M. Gallo ${ }^{{ }^{*}}$

${ }^{1}$ Clinic of Masticatory Disorders, Removable Prosthodontics and Special Care,

Center of Dental Medicine, University of Zurich

Plattenstrasse 11

$\mathrm{CH}-8032$ Zurich, Switzerland

Phone+41-44-6343226

Fax +41-44-6344302

e-mail luigi.gallo@zzm.uzh.ch

${ }^{2}$ Oral Biotechnology \& Bioengineering, Department of Cranio-Maxillofacial Surgery, University Hospital Zurich, Frauenklinikstrasse 24, CH-8091 Zürich, Switzerland

${ }^{3}$ Laboratory for Surface Science and Technology, Department of Materials, ETH Zurich, Wolfgang-Pauli-Strasse 10, CH-8093 Zurich, Switzerland

${ }^{4}$ Clinic of Preventive Dentistry, Parodontology and Cariology, Center of Dental Medicine, University of Zurich, Plattenstrasse 11, CH-8032 Zurich, Switzerland

Number of words in the abstract: 250

Number of words in the text including abstract and acknowledgments: 2894

Number of tables: 0

Number of figures: 4

Number of references: 48

${ }^{*}$ Corresponding author 


\begin{abstract}
Articular cartilage undergoes complex loading modalities generally including sliding, rolling and plowing (i.e. the compression by a condyle normally to the tissue surface under simultaneously tangential displacement, thus generating a tractional force due to tissue deformation). Although in in vivo studies it was shown that excessive plowing can lead to osteoarthritis, little quantitative experimental work on this loading modality and its mechanobiological effects is available in the literature. Therefore, a rolling/plowing explant test system has been developed to study the effect on pristine cartilage of plowing at different perpendicular forces.
\end{abstract}

Cartilage strips harvested from bovine nasal septa of 12-months-old calves were subjected for 2 hours to a plowing-regime with indenter normal force of 50 or $100 \mathrm{~N}$ and a sliding speed of $10 \mathrm{~mm} \mathrm{~s}^{-1} .50 \mathrm{~N}$ produced a tractional force of $1.2 \pm 0.3 \mathrm{~N}$, whereas $100 \mathrm{~N}$ generated a tractional force of $8.0 \pm 1.4 \mathrm{~N}$. Furthermore, quantitativereal-time polymerase chain reaction experiments showed that TIMP-1 was $2.5 \mathrm{x}$ upregulated after $50 \mathrm{~N}$ plowing and 2x after $100 \mathrm{~N}$ plowing, indicating an ongoing remodeling process. The expression of Collagen type I was not affected after $50 \mathrm{~N}$ plowing but it was up-regulated (6.6x) after $100 \mathrm{~N}$ plowing, suggesting a possible progression to an injury stage of the cartilage, as previously reported in cartilage of osteoarthritic patients. We conclude that plowing as performed by our mimetic system at the chosen experimental parameters induces changes in gene expression depending on the tractional force, which, in turn, relates to the applied normal force.

Keywords: cartilage, plowing, friction, osteoarthritis, cartilage homeostasis 


\section{Introduction}

Synovial joints are composed of a mechanical system comprising bones, cartilage, tendons and ligaments. These elements interact and cooperate allowing joint movement, which is also facilitated by synovial fluid-the joint lubricant. Within the mechanical system, each element has a specific function: bones provide support, cartilage — placed on adjacent bones — provides a sliding surface and adsorbs shocks, tendons link muscles and bones, while ligaments stabilize the joint (Cawston and Young, 2010).

It has been demonstrated that in pathological conditions such as in osteoarthritis $(\mathrm{OA})$, elevated expression and activities of proteolytic enzymes cause destruction of articular cartilage and ultimately of the underlying subchondral bone (Goldring and Marcu, 2009; Martel-Pelletier et al., 2008; Williams et al., 2010). Patients affected by this degenerative disease suffer from severe pain and movement impairment with a general decrease in the quality of life (Tellini et al., 2008).

Since injurious mechanical stress has been recognized as one of the causes of OA development, cartilage overloading has been the focus of a number of studies aimed at mimicking unfavorable mechanical conditions that cartilage could experience (Fitzgerald et al., 2006a; Kurz et al., 2005; Lin et al., 2004; Patwari et al., 2001; Torzilli et al., 2010). Although these studies provided insight into the biological response of cartilage to static and cyclic loading of different duration, normal force magnitude and frequency, their uni-axial design presents some limitations.

Drop-tower devices have been built and described by Jeffrey et al. (Jeffrey et al., 1995) and Repo and Finlay (Repo and Finlay, 1977). A common disadvantage of these devices was that the strain rate during compression could not be measured. Later, other experiments have been performed by using systems with computer- 
controlled motor-driven plates that were able to control load or displacement during injury (D'Lima et al., 2001; Loening et al., 2000; Quinn et al., 1998; Torzilli et al., 1997).

Indeed, in vivo, articular cartilage undergoes more complex loading modalities than pure uni-axial compression, including predominantly a combination of sliding, rolling and plowing (Kuroda et al., 2009; Williams et al., 2010). Plowing has been earlier described as the deformation of synovial cartilage due to the combination of compression and tangential motion of the contacting bones (Linn, 1967). In in vivo studies on dogs, it was shown that excessive plowing can be considered to be a cause of OA onset (Anderst and Tashman, 2009). Moreover, it has been reported that plowing is the dominant mechanism leading to tangential tractional forces in synovial cartilage (Chan et al., 2010). However, little quantitative experimental work on plowing and its mechanobiological effects has been reported in the literature.

Plowing has been extensively investigated in the temporomandibular joint (TMJ), in particular in its fibrocartilaginous disc, which is subject to compression by the underlying mandibular condyle that in general translates and rotates simultaneously (Donzelli et al., 2004; Mow et al., 1993; Nickel et al., 2009; Adams et al., 2009; Detamore and Athanasiou, 2003; Singh and Detamore, 2009; Tanaka, 2003). In our previous work, the complex TMJ disc deformation, and thus indirectly its loading, has been studied quantitatively from in vivo data by coupling magnetic resonance imaging (MRI) and jaw-tracking of human subjects (Gallo et al., 2000; Gallo, 2005; Gallo et al., 2006; Palla et al., 2003).

This has led to the idea of replicating this information experimentally on live tissue in a bench-top apparatus, a so-called rolling/plowing explant test system (RPETS), in order to study the biological reaction of cartilage to this type of loading (Colombo et 
al., 2011; Gallo et al., 2009; Colombo and Gallo, 2008). The RPETS is able to mimic plowing effects occurring in vivo that result from the combination of an applied normal force and the sliding of a condyle on a cartilage sample (Fig. 1). The cartilage sample is placed on the bottom of a tank and kept alive by a culture medium.

For a first set of experiments, bovine nasal septum cartilage was chosen as model tissue since it is abundantly available from abattoirs, it delivers sample of convenient size and shape and is pristine. RPETS settings and parameterization have been the focus of this study in order to detect whether gene expression in bovine nasal septum cartilage is dependent on tractional forces due to plowing.

The objectives of this study were therefore to apply plowing at different normal forces to pristine cartilage collected from bovine nasal septa and analyze differences in the resulting tractional forces and gene expression. 


\section{Materials and Methods}

\section{Tissue harvesting and experimental set-up}

Nasal septa of 12-month-old calves, both male and female, were provided by a local abattoir within 4 hours of slaughter. Under sterile conditions and using a custommade cutter, cartilage strips $(60 \times 17 \times 2 \mathrm{~mm})(\mathrm{LxW} \times \mathrm{H})$ and control cartilage explants

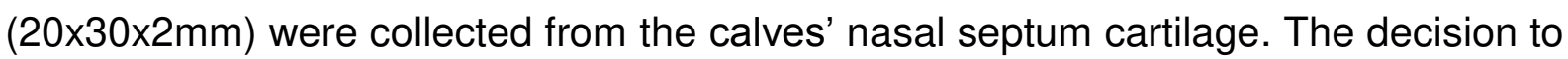
have a smaller control is supported by the importance of having both samples, the one to be plowed and the control explant from the same septum. Altogether nine cartilage strips and nine relative control explants were harvested, each pair from a separate nasal septum. Control samples and cartilage strips were washed in Dulbecco's Phosphate-Buffered Saline (D-PBS) and equilibrated overnight in Dulbecco's Modified Eagle's Medium (DMEM) supplemented with 10\% fetal bovine serum, $10 \mathrm{mM}$ Hepes buffer, $0.1 \mathrm{mM}$ nonessential amino acids, 100 units $/ \mathrm{ml}$ penicillin, $100 \mu \mathrm{g} / \mathrm{ml}$ streptomycin and $0.25 \mu \mathrm{g} / \mathrm{ml}$ amphotericin B.

In order to perform the plowing, cartilage strips were glued at the extremities to a Plexiglas support by means of cyanoacrylate glue.

The plowing was performed either with $50 \mathrm{~N}$ or $100 \mathrm{~N}$ applied normal force. These values correspond to physiological load in an in vivo situation (Boyd et al., 1990; Sellers and Crompton, 2004).

The plowing was performed in DMEM for 2 hours at room temperature $\left(\approx 23^{\circ} \mathrm{C}\right)$, in a sterile hood. More in detail, four strips were plowed at $50 \mathrm{~N}$ while five strips were subjected to $100 \mathrm{~N}$ plowing. It consisted of the reciprocating sliding (displacement: 40 $\mathrm{mm}$, tangential speed: $10 \mathrm{~mm} / \mathrm{sec}$ and a constant normal force: 50 or $100 \mathrm{~N}$ ) of a fixed, cylindrical indenter ( $\varnothing 25 \mathrm{~mm}$; stainless steel) on the cartilage strip. Plowing was performed as a regular cyclic motion of the indenter (Fig. 2) summarized as the 
sequence of the following steps: a) vertical descent of the indenter to contact the cartilage; b) vertical indentation to reach the desired normal force; c) horizontal displacement of the indenter at the constant desired speed while maintaining the normal force constant; d) lifting of the indenter to the initial position. The profiles of dynamic loading were obtained by plotting the values for the stored position, speed and forces in the RPETS indenter on the horizontal and vertical axes.

The RPETS is equipped with linear variable differential transformers (LVDTs) and with two independent load-cells placed respectively in the horizontal and in the vertical axes. It can move its indenter in the horizontal and vertical direction, and vary the applied forces and the sliding speeds. Furthermore, a software application based on LABVIEW 8.2 (National Instruments, Austin, Texas) allows the user to program the experimental set-up, to monitor the load in real time, and to record and store all experimental data.

During plowing, the control cartilage samples were placed as free swelling explants in the same medium in which the loading occurred. In order to monitor macroscopic changes in the cartilage, the length, the width and the thickness of the strips were measured before and after plowing. After plowing, cartilage strips and corresponding controls (non-loaded cartilage) were treated for RNA extraction and the gene expression studied by means of quantitative, real-time, polymerase-chain-reaction methods (qRT-PCR, see below).

\section{RNA extraction and gene-expression study}

Within 10 minutes after plowing completion, three experimental samples per cartilage strip were collected from the central region (i.e. excluding the two extremities glued), snap frozen together with the control samples in liquid nitrogen, and stored at $-80^{\circ} \mathrm{C}$ until RNA extraction was performed. RNA was extracted according to modified 
version of the method reported by Davidson et al. (Davidson et al., 2006). Briefly, sliced cartilage explants were homogenized twice for $1 \mathrm{~min}$ in $800 \mu \mathrm{L}$ TRIzol reagent (Invitrogen, Inc., Carlsbad, CA 92008). After 5 min equilibration at room temperature, $200 \mu \mathrm{L}$ chloroform were added and the tubes were vigorously shaken, mixed and incubated for $2 \mathrm{~min}$ at room temperature. After centrifugation at $9500 \mathrm{~g}$ for $30 \mathrm{~min}$ at 4 ${ }^{\circ} \mathrm{C}$, the obtained aqueous layers were extracted again with $200 \mu \mathrm{L}$ chloroform and treated as previously described. After the addition of $500 \mu \mathrm{L}$ isopropanol, samples were incubated for $10 \mathrm{~min}$ at room temperature and successively centrifuged at $9500 \mathrm{~g}$ for $30 \mathrm{~min}$ at $4{ }^{\circ} \mathrm{C}$. Pellets were re-suspended in $900 \mu \mathrm{L}$ lysis buffer (RNeasy Mini Kit; Qiagen $\mathrm{GmbH}$, Hilden, Germany) supplemented with $90 \mu \mathrm{L} \quad \beta$ mercaptoethanol (Sigma-Aldrich, Inc., St. Louis, MO 63103). $900 \mu \mathrm{L}$ ethanol (75\%) were added and RNA was purified using Qiagen RNeasy mini-kit, while genomic DNA was digested with a DNase kit (Qiagen $\mathrm{GmbH}$ ) following the manufacturer's instructions. Reverse transcription was performed with random hexamer primers using a $1^{\text {st }}$ Strand cDNA Synthesis Kit for RT-PCR (AMV) (Roche Diagnostics AG, Rotkreuz, Switzerland), following the manufacturer's instructions. Real-time quantitative PCR was performed on 96-well plates using an iCycler Real-Time Detection System (iQ5, Bio-Rad Laboratories, Inc., Hercules, CA 94547) and the reactions were carried out using QuantiFast ${ }^{\mathrm{TM}}$ SYBR® Green PCR kit (Qiagen $\mathrm{GmbH}$ ). Target genes of the RT-qPCR, amplified by means of primers (used at a concentration of $20 \mu \mathrm{M}$ ) from Fitzgerald et al. (Fitzgerald et al., 2006b) were: the extracellular matrix proteins aggrecan (Agg), collagen type-I (Coll1), collagen type-II (Coll2), fibronectin (Fn) and stromelysin-1 (MMP-3) as well as its inhibitor (TIMP-1), whereas the housekeeping genes were glyceraldehyde-3-phosphate dehydrogenase (G3PDH) and ribosomal RNA 18S (18S rRNA). 
MMP-3 has been chosen as indicator of enzymatic activity since it digests collagens, proteoglycans, and other extracellular proteins and additionally activates the proforms of other MMPs and aggrecanase II (Cawston and Wilson, 2006; Echtermeyer et al., 2009; Murphy et al., 2002). Consequentely since TIMP-1 inhibit the activity of MMP-3, its gene expression has also been studied.

The choice of two housekeeping genes was taken after evaluation of previous publications reporting a better accuracy of this experimental set-up compared to the use of a single housekeeping gene (Santos and Duarte, 2008; Vandesompele et al., 2002).

\section{Statistical analysis.}

All plowing experiments were carried out in replicate; 4 strips were plowed at $50 \mathrm{~N}$ while 5 strips were subjected to $100 \mathrm{~N}$ plowing. Each strip and the corresponding control explant were from a different nasal septum. For the qRT-PCR the plowed samples were collected in triplicate from each strip, thus yielding 12 samples for $50 \mathrm{~N}$ and 15 samples for $100 \mathrm{~N}$. Results are expressed as the mean \pm S.E. Statistical differences were analyzed using Student's $t$ test. 


\section{Results}

Tractional forces, defined as the result of frictional and sliding forces produced by the deformation of the cartilage, are shown in black for the plowing at $50 \mathrm{~N}$ and in blue for plowing at $100 \mathrm{~N}$ in Fig.3. During plowing with the lower normal force, the tractional force was $1.2 \pm 0.3 \mathrm{~N}$, while with the higher normal force the tractional force increased strongly ( $8.0 \pm 1.6 \mathrm{~N})$ (Fig. $3 \mathrm{C})$.

From a macroscopic point of view, an increase in the entire cartilage strip length $(\Delta \ell)$ was observed at both the applied normal forces: strips plowed at $50 \mathrm{~N}$ had a $\Delta \ell$ of 1.0 $\pm 0.06 \mathrm{~mm}$ while strips plowed at $100 \mathrm{~N}$ had a $\Delta \ell$ of $1.9 \pm 0.29 \mathrm{~mm}$. This absolute length increase corresponded to a relative elongation of $1.5 \pm 0.2 \%$ and $3 \pm 0.7 \%$ for $50 \mathrm{~N}$ and $100 \mathrm{~N}$, respectively. The compressive strain of the samples during plowing was on average $32 \pm 4 \%$ for $50 \mathrm{~N}$ normal force and $65 \pm 5 \%$ for $100 \mathrm{~N}$ normal force.

Plowing with lower applied normal force $(50 \mathrm{~N})$ did not induce significant changes in the chondrocyte gene expression, with the exception of TIMP-1, which was slightly up-regulated (2.5 fold) (Fig.4). Strips plowed at higher normal forces (100 N) showed up-regulation (6.6 fold) of Coll1 and slight up-regulation of both MMP-3 (2.5 fold) and TIMP-1 (2.1 fold) (Fig.4). The other studied genes (Agg, Coll2 and Fn) did not appear to be affected by plowing at either of the applied normal forces. 


\section{Discussion}

For this work, we have developed a novel motor-driven system, RPETS, that is able to perform plowing experiments on bovine nasal septum cartilage explants (Colombo et al., 2011). Cartilage strips shaped from bovine nasal septum cartilage have been subjected to plowing for 2 hours at room temperature using the RPETS indenter, which slides horizontally at a constant speed of $10 \mathrm{~mm} / \mathrm{sec}$, and applies normal forces of 50 or $100 \mathrm{~N}$. In order to study the gene-expression variation caused by plowing, qRT-PCR has been performed immediately after plowing.

In agreement with previously reported results on cyclic compression of cartilage explants (Fitzgerald et al., 2006b), qRT-PCR showed that cartilage strips plowed with a normal force of $50 \mathrm{~N}$ exhibits up-regulation (2.5 fold) of TIMP-1. In general, TIMPs prevent cartilage breakdown by tightly binding the active MMP (Cawston and Young, 2010; Matsuyama, 1999). It has been reported that in lightly damaged healthy cartilage the levels of MMPs are reduced, whereas those of TIMP are increased (Martel-Pelletier et al., 2008). The result obtained in the present study for TIMP-1 upregulation could thus indicate that at $50 \mathrm{~N}$ plowing, cartilage breakdown does not occur but rather that cartilage regulates its metabolic activity by blocking the possible ongoing catabolism and undergoing a normal process of remodeling (Gomez et al., 1997; Woessner, Jr., 1991).

Cartilage strips plowed with a normal force of $100 \mathrm{~N}$ showed slight up-regulation of both MMP-3 (2.5 fold) and TIMP-1 (2.1 fold) and a significant up-regulation of Coll1. It is known that in OA, chondrocytes are subjected to a "dedifferentiation" process, consisting of a change to a fibroblast-like phenotype. This change is characterized by the synthesis of Coll1 as a replacement for Coll2 (Miosge et al., 2004; Sandell and Aigner, 2001). This suggests that plowing with applied normal force of $100 \mathrm{~N}$ has a 
significant destructive effect on cartilage explants. Furthermore, since plowing with a force of $100 \mathrm{~N}$ induced the production of a tractional force reaching $8 \mathrm{~N}$, we conclude that the tractional force plays an important role in cartilage injury during plowing.

Interestingly, we also observe that the length of strips plowed at $100 \mathrm{~N}$ increased by around $2 \mathrm{~mm}$, meaning that the strips are deformed beyond the elastic region. This finding is in agreement with Tanaka and van Eijden, who studied the physiological stretching to which the TMJ disc is subjected in vivo (Tanaka, 2003), suggesting that we have reached the ultimate strength as measured in the TMJ disc.

An advantage of our novel RPETS rolling-plowing system is that different parameters, such as indenter speed and applied normal force can be set. Other parameters that could be varied are the plowing duration as well as the post-plowing equilibration time of cartilage explants. Further RPETS improvements could include the ability to carry out plowing at physiological temperature.

In the present study the effect of plowing with different applied normal forces on pristine cartilage (bovine nasal septum) has been reported. The cartilage deformation, measured as the increase in the cartilage strips length, was dependent on the magnitude of the applied normal force. Moreover, profiles of the tractional forces generated during plowing have been described: the higher the applied normal forces, the higher the generated tractional forces. Furthermore, the results reproducibly suggest that plowing with higher normal force might be harmful to the cartilage explants, as indicated by the up-regulation of type I collagen and of the catabolic enzyme MMP-3. This up-regulation is only a hint of a possible process that needs further and deeper analysis. 


\section{Acknowledgments}

The study was supported by grant No. 325200-110067 from the Swiss National Science Foundation. 


\section{References}

Adams, M. A., Dolan, P., McNally, D. S., (2009). The internal mechanical functioning of intervertebral discs and articular cartilage, and its relevance to matrix biology. Matrix Biol 28, 384-389.

Anderst, W. J., Tashman, S., (2009). The association between velocity of the center of closest proximity on subchondral bones and osteoarthritis progression. J.Orthop.Res. 27, 71-77.

Boyd, R. L., Gibbs, C. H., Mahan, P. E., Richmond, A. F., Laskin, J. L., (1990). Temporomandibular joint forces measured at the condyle of Macaca arctoides. Am.J.Orthod.Dentofacial Orthop. 97, 472-479.

Cawston, T. E., Wilson, A. J., (2006). Understanding the role of tissue degrading enzymes and their inhibitors in development and disease. Best Pract Res Clin Rheumatol 20, 983-1002.

Cawston, T. E., Young, D. A., (2010). Proteinases involved in matrix turnover during cartilage and bone breakdown. Cell Tissue Res 339, 221-235.

Chan, S. M., Neu, C. P., Duraine, G., Komvopoulos, K., Reddi, A. H., (2010). Atomic force microscope investigation of the boundary-lubricant layer in articular cartilage. Osteoarthritis.Cartilage. 18, 956-963.

Colombo, V., Correro, M. R., Riener, R., Weber, F. E., Gallo, L. M., (2011). Design, construction and validation of a computer controlled system for functional loading of soft tissue.

Colombo, V., Gallo, L. M., (2008). Viscoelastic Characterization of Bovine Nasal Septum as Model for TMJ Disc Mechanobiology.

D'Lima, D. D., Hashimoto, S., Chen, P. C., Colwell, C. W., Jr., Lotz, M. K., (2001). Impact of mechanical trauma on matrix and cells. Clin.Orthop.Relat Res. S90-S99.

Davidson, R. K., Waters, J. G., Kevorkian, L., Darrah, C., Cooper, A., Donell, S. T., Clark, I. M., (2006). Expression profiling of metalloproteinases and their inhibitors in synovium and cartilage. Arthritis Res.Ther. 8, R124.

Detamore, M. S., Athanasiou, K. A., (2003). Structure and function of the temporomandibular joint disc: implications for tissue engineering. J Oral Maxillofac Surg 61, 494-506.

Donzelli, P. S., Gallo, L. M., Spilker, R. L., Palla, S., (2004). Biphasic finite element simulation of the TMJ disc from in vivo kinematic and geometric measurements. J.Biomech. 37, 1787-1791.

Echtermeyer, F., Bertrand, J., Dreier, R., Meinecke, I., Neugebauer, K., Fuerst, M., Lee, Y. J., Song, Y. W., Herzog, C., Theilmeier, G., Pap, T., (2009). Syndecan-4 regulates ADAMTS-5 activation and cartilage breakdown in osteoarthritis. Nat.Med. 15, 1072-1076. 
Fitzgerald, J. B., Jin, M., Grodzinsky, A. J., (2006a). Shear and compression differentially regulate clusters of functionally related temporal transcription patterns in cartilage tissue. J.Biol.Chem. 281, 24095-24103.

Fitzgerald, J. B., Jin, M., Grodzinsky, A. J., (2006b). Shear and compression differentially regulate clusters of functionally related temporal transcription patterns in cartilage tissue. J.Biol.Chem. 281, 24095-24103.

Gallo, L. M., (2005). Modeling of temporomandibular joint function using MRI and jaw-tracking technologies--mechanics. Cells Tissues Organs 180, 54-68.

Gallo, L. M., Chiaravalloti, G., Iwasaki, L. R., Nickel, J. C., Palla, S., (2006). Mechanical work during stress-field translation in the human TMJ. J Dent Res 85, 1006-1010.

Gallo, L. M., Correro, M. R., Colombo, V., (2009). A mechanobiological model of the TMJ: response of the disc to plowing.

Gallo, L. M., Nickel, J. C., Iwasaki, L. R., Palla, S., (2000). Stress-field translation in the healthy human temporomandibular joint. J.Dent.Res. 79, 1740-1746.

Goldring, M. B., Marcu, K. B., (2009). Cartilage homeostasis in health and rheumatic diseases. Arthritis Res.Ther. 11, 224.

Gomez, D. E., Alonso, D. F., Yoshiji, H., Thorgeirsson, U. P., (1997). Tissue inhibitors of metalloproteinases: structure, regulation and biological functions. Eur $\mathrm{J}$ Cell Biol 74, 111-122.

Jeffrey, J. E., Gregory, D. W., Aspden, R. M., (1995). Matrix damage and chondrocyte viability following a single impact load on articular cartilage. Arch.Biochem.Biophys. 322, 87-96.

Kuroda, S., Tanimoto, K., Izawa, T., Fujihara, S., Koolstra, J. H., Tanaka, E., (2009). Biomechanical and biochemical characteristics of the mandibular condylar cartilage. Osteoarthritis.Cartilage. 17, 1408-1415.

Kurz, B., Lemke, A. K., Fay, J., Pufe, T., Grodzinsky, A. J., Schunke, M., (2005). Pathomechanisms of cartilage destruction by mechanical injury. Ann.Anat. 187, 473485.

Lin, P. M., Chen, C. T. C., Torzilli, P. A., (2004). Increased stromelysin-1 (MMP-3), proteoglycan degradation (3B3- and 7D4) and collagen damage in cyclically loadinjured articular cartilage. Osteoarthritis and Cartilage 12, 485-496.

Linn, F. C., (1967). Lubrication of animal joints. I. The arthrotripsometer. J.Bone Joint Surg.Am. 49, 1079-1098.

Loening, A. M., James, I. E., Levenston, M. E., Badger, A. M., Frank, E. H., Kurz, B., Nuttall, M. E., Hung, H. H., Blake, S. M., Grodzinsky, A. J., Lark, M. W., (2000). Injurious mechanical compression of bovine articular cartilage induces chondrocyte apoptosis. Arch Biochem Biophys 381, 205-212. 
Martel-Pelletier, J., Boileau, C., Pelletier, J. P., Roughley, P. J., (2008). Cartilage in normal and osteoarthritis conditions. Best Pract Res Clin Rheumatol 22, 351-384.

Matsuyama, T., (1999). Tissue inhibitor of metalloproteinases-1 and matrix metalloproteinase-3 in Japanese healthy children and in Kawasaki disease and their clinical usefulness in juvenile rheumatoid arthritis. Pediatr Int 41, 239-245.

Miosge, N., Hartmann, M., Maelicke, C., Herken, R., (2004). Expression of collagen type I and type II in consecutive stages of human osteoarthritis. Histochem Cell Biol $122,229-236$.

Mow, V. C., Ateshian, G. A., Spilker, R. L., (1993). Biomechanics of diarthrodial joints: a review of twenty years of progress. J.Biomech.Eng 115, 460-467.

Murphy, G., Knauper, V., Atkinson, S., Butler, G., English, W., Hutton, M., Stracke, J., Clark, I., (2002). Matrix metalloproteinases in arthritic disease. Arthritis Res 4 Suppl 3, S39-S49.

Nickel, J. C., Iwasaki, L. R., Beatty, M. W., Marx, D. B., (2009). Tractional forces on porcine temporomandibular joint discs. J.Dent.Res. 88, 736-740.

Palla, S., Gallo, L. M., Gossi, D., (2003). Dynamic stereometry of the temporomandibular joint. Orthod Craniofac Res 6 Suppl 1, 37-47.

Patwari, P., Fay, J., Cook, M. N., Badger, A. M., Kerin, A. J., Lark, M. W., Grodzinsky, A. J., (2001). In vitro models for investigation of the effects of acute mechanical injury on cartilage. Clin Orthop Relat Res S61-S71.

Quinn, T. M., Grodzinsky, A. J., Hunziker, E. B., Sandy, J. D., (1998). Effects of injurious compression on matrix turnover around individual cells in calf articular cartilage explants. J Orthop Res 16, 490-499.

Repo, R. U., Finlay, J. B., (1977). Survival of articular cartilage after controlled impact. J.Bone Joint Surg.Am. 59, 1068-1076.

Sandell, L. J., Aigner, T., (2001). Articular cartilage and changes in arthritis. An introduction: cell biology of osteoarthritis. Arthritis Res 3, 107-113.

Santos, A. R., Duarte, C. B., (2008). Validation of internal control genes for expression studies: effects of the neurotrophin BDNF on hippocampal neurons. J.Neurosci.Res. 86, 3684-3692.

Sellers, W. I., Crompton, R. H., (2004). Using sensitivity analysis to validate the predictions of a biomechanical model of bite forces. Ann Anat 186, 89-95.

Singh, M., Detamore, M. S., (2009). Biomechanical properties of the mandibular condylar cartilage and their relevance to the TMJ disc. J Biomech 42, 405-417.

Tanaka, E., (2003). Biomechanical behavior of the temporomandibular joint disc. Crit Rev Oral Biol Med 14, 138-150. 
Tellini, A., Ciccone, V., Blonna, D., Rossi, R., Marmotti, A., Castoldi, F., (2008). Quality of life evaluation in patients affected by osteoarthritis secondary to congenital hip dysplasia after total hip replacement. J Orthop Traumatol 9, 155-158.

Torzilli, P. A., Bhargava, M., Park, S., Chen, C. T. C., (2010). Mechanical load inhibits IL-1 induced matrix degradation in articular cartilage. Osteoarthr Cartilage 18, 97105.

Torzilli, P. A., Grigiene, R., Huang, C., Friedman, S. M., Doty, S. B., Boskey, A. L., Lust, G., (1997). Characterization of cartilage metabolic response to static and dynamic stress using a mechanical explant test system. J Biomech 30, 1-9.

Vandesompele, J., De, P. K., Pattyn, F., Poppe, B., Van, R. N., De, P. A., Speleman, F., (2002). Accurate normalization of real-time quantitative RT-PCR data by geometric averaging of multiple internal control genes. Genome Biol. 3, RESEARCH0034.

Williams, G. M., Chan, E. F., Temple-Wong, M. M., Bae, W. C., Masuda, K., Bugbee, W. D., Sah, R. L., (2010). Shape, loading, and motion in the bioengineering design, fabrication, and testing of personalized synovial joints. J.Biomech. 43, 156-165.

Woessner, J. F., Jr., (1991). Matrix metalloproteinases and their inhibitors in connective tissue remodeling. FASEB J 5, 2145-2154. 
Fig. 1 Schematic representation of the dynamic loading mimicking the plowing effect performed by the RPETS indenter on a cartilage strip. The combination of an applied normal force and of the sliding induces cartilage bending.

Fig. 2 Schematic representation of the condyle plowing performed by the RPETS indenter on a cartilage strip. A) The indenter moves vertically until it contacts the cartilage; B-D) the indenter is displaced horizontally at the desired speed while keeping constant the applied normal force; D-E) the indenter leaves the cartilage and returns to its initial position

Fig. 3 Plowing profiles during an arbitrary chosen period of $180 \mathrm{sec}$. A: the applied normal force is $50 \mathrm{~N}$ (pink line); the lower black line is the tractional force measured in the horizontal axis. B: the applied normal force is $100 \mathrm{~N}$ (green line); the blue line is the tractional force. In $\mathrm{C}$ the tractional forces for plowing at $50 \mathrm{~N}$ (black) or $100 \mathrm{~N}$ (blue) are compared. For $50 \mathrm{~N}$ normal force, the fluctuation of the tractional force depends mostly on the fluctuation of the normal force but, for these low force levels, also noise effects are present.

Fig. 4 Cartilage gene expression changes after plowing at $50 \mathrm{~N}$ (white bars; $\mathrm{n}=4$ plowed strips) or $100 \mathrm{~N}$ (grey bars; $\mathrm{n}=5$ plowed strips) measured within 10 minutes after loadings. Plowing performed with higher normal forces caused stronger changes in the gene expression than plowing with lower normal force. Each strip and the relative control sample were from a separate bovine nasal septum, and for each plowed strip three similarly treated explants were pooled for RNA extraction. Expression levels are normalized to those of the control, which was non-loaded free swelling explants ( $\star$ indicates the difference of plowing effect at 50 or $100 \mathrm{~N}$, on the gene expression; $\mathrm{P}<0.05$ ). 

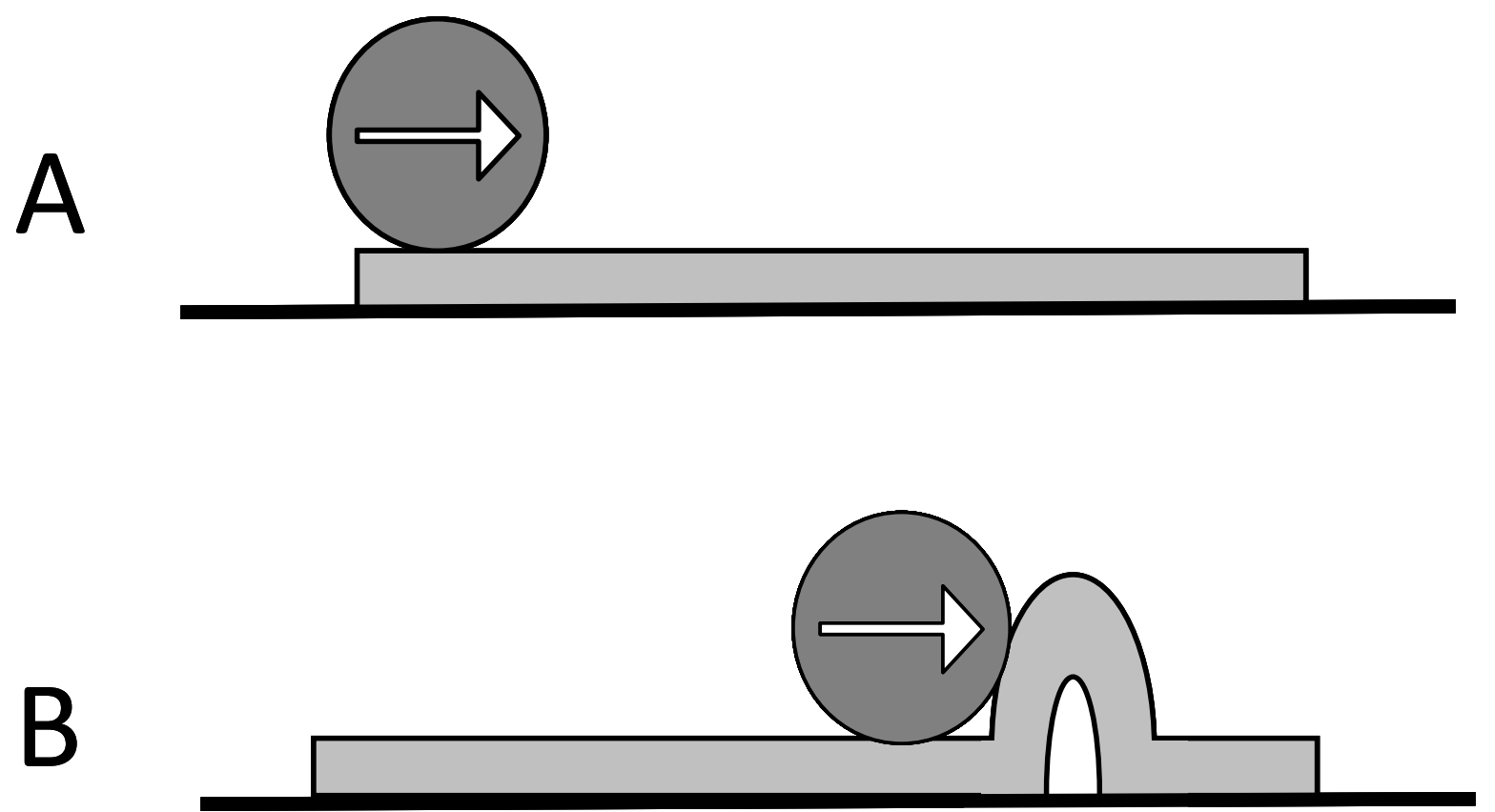
A
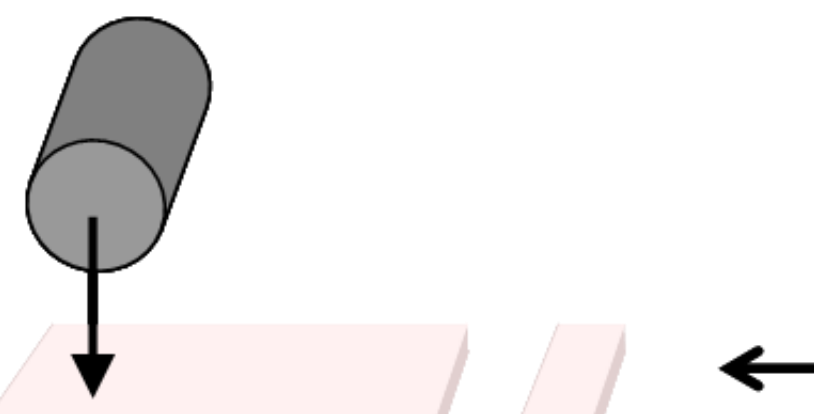

B

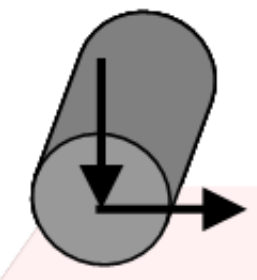

C

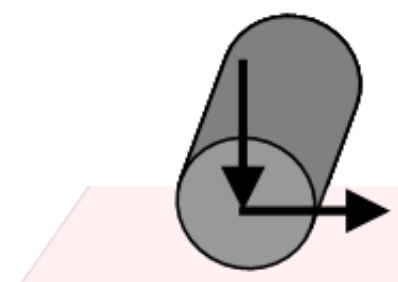

D

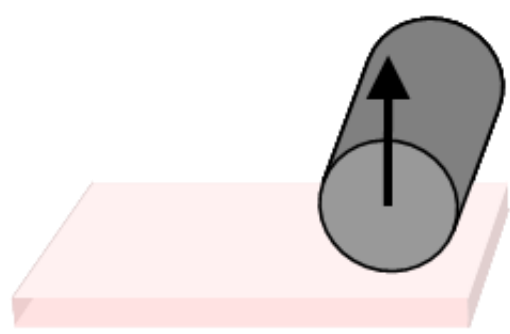

E

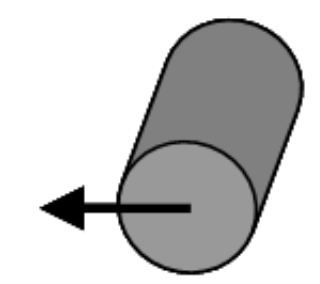



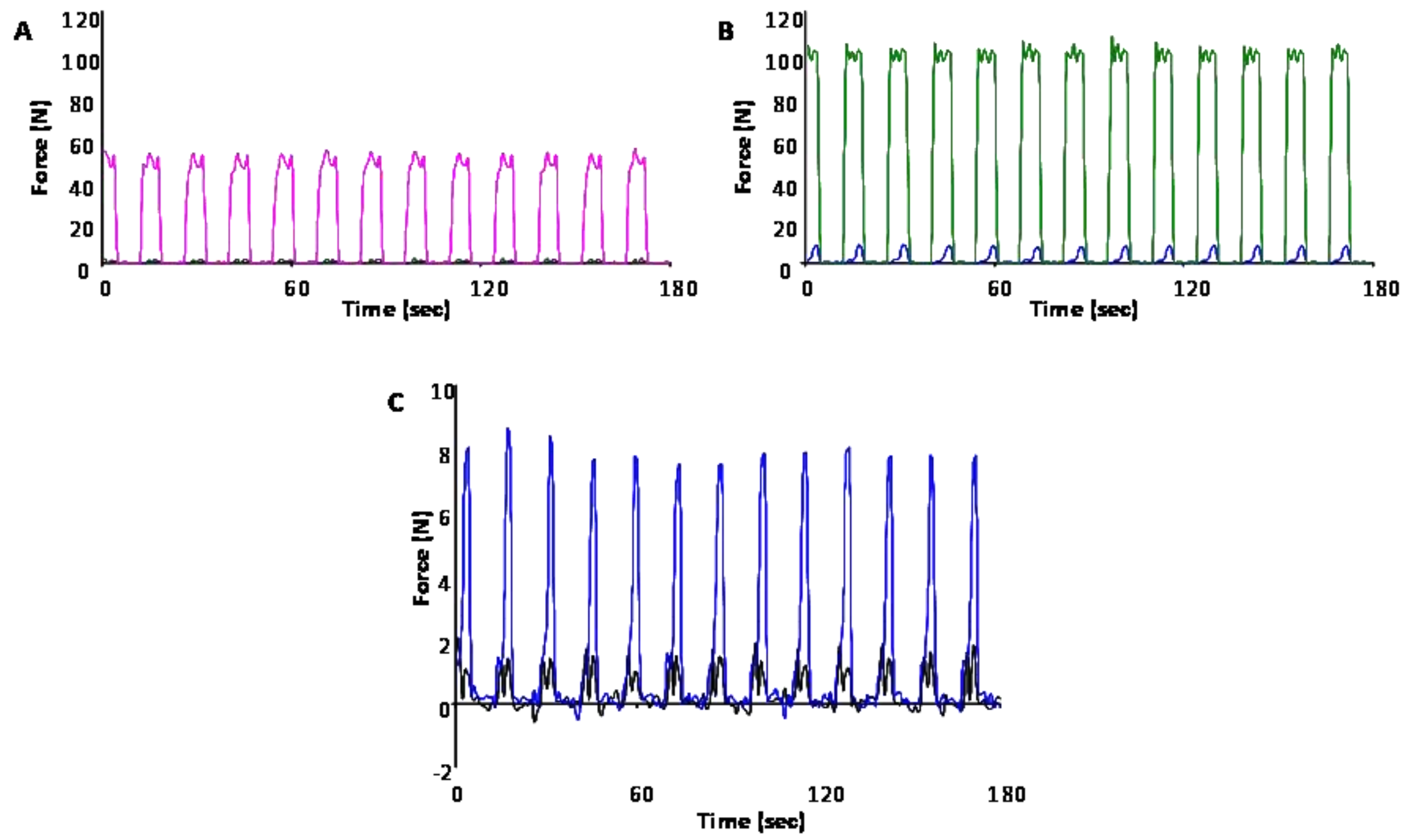


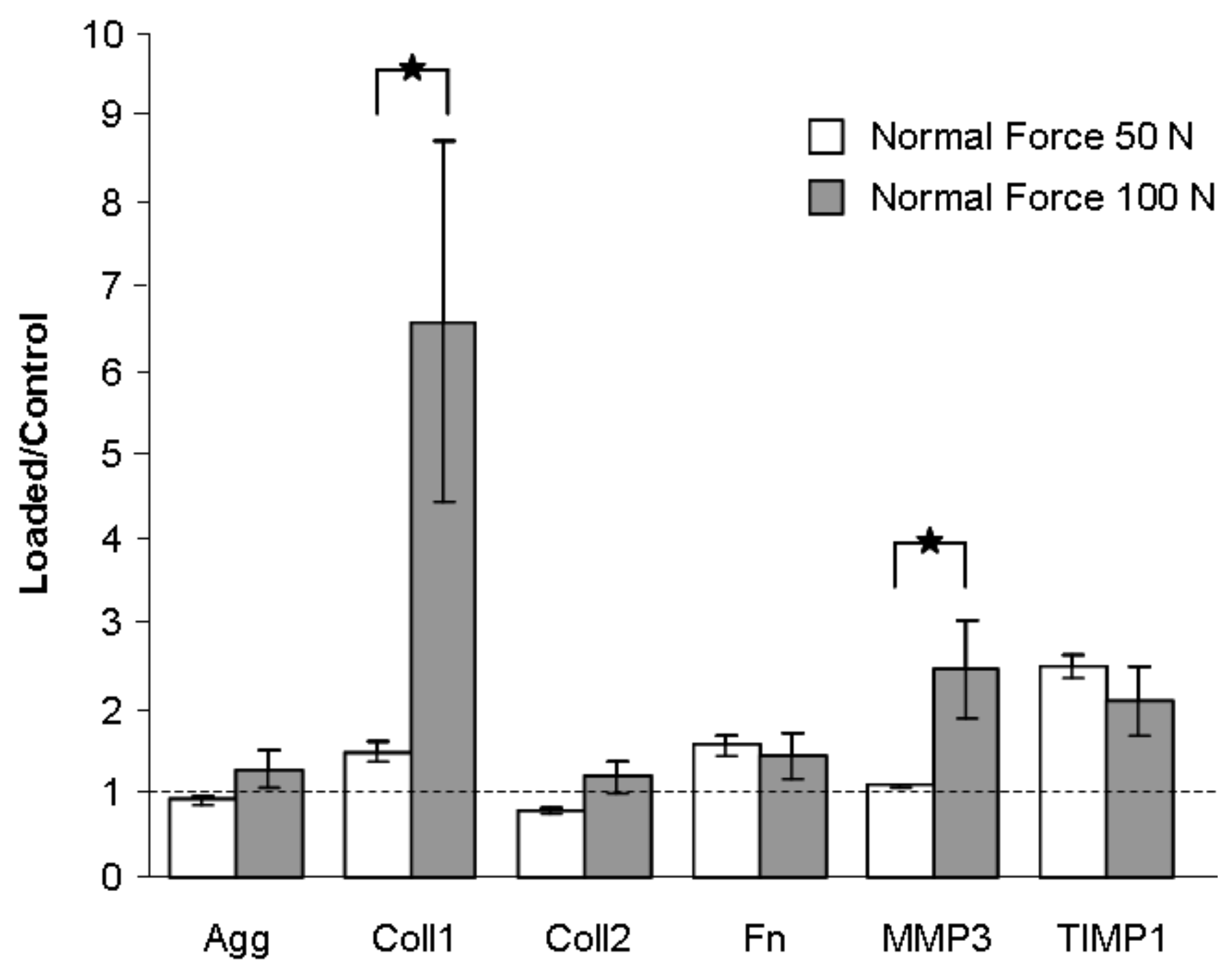

